\title{
Semblanza de Daniela Antúnez
}

Daniela Antúnez se graduó de Profesora en Letras en la Facultad de Humanidades y Artes de la Universidad Nacional de Rosario con los máximos honores, obteniendo el "Premio Academia Argentina de Letras" al mejor promedio egresado en el año 1989. Apenas unos años más tarde inició su carrera docente universitaria, en 1992, tras ser designada por concurso Jefa de Trabajos Prácticos de Lengua Griega II en la carrera de Letras de la misma Universidad, y, en 2008, fue nombrada Profesora Adjunta en esa misma cátedra. A partir de 2005, comenzó a ejercer también el cargo de Profesora Titular de Griego en el Profesorado de Filosofía del Instituto Superior "Don Bosco" de Rosario.

A la lengua y la cultura griegas antiguas dedicó desde el comienzo su gran vocación. A partir de su labor en la cátedra y desde los diversos seminarios que dictó en la carrera de la Licenciatura en Letras, trabajó arduamente por implementar nuevos métodos en la enseñanza de la lengua y por incorporar perspectivas teóricas actualizadas en el abordaje de la literatura griega. El amor por el griego se conjugó con su profundo compromiso docente, al punto que los alumnos que pasaban por sus aulas rápidamente la consideraron un referente por su dedicación y entrega. Su posicionamiento ideológico y la búsqueda por revitalizar su ámbito de estudio la llevaron a socializar sin miramientos los espacios de trabajo que iba generando y los recursos de los que disponía. Ajena a las presunciones catedráticas y desprendida de toda solemnidad y afectación, supo darle nueva vida a los textos griegos en más de un aula de Rosario. Sus apasionadas intervenciones en el ejercicio cotidiano de interpretación y traducción de los textos poéticos lograron rejuvenecer en esta Facultad la vocación por los estudios helénicos.

En el ámbito de la investigación, fue becaria de CONICET entre 1996 y 2001, lo que le permitió desarrollar sus investigaciones sobre la poesía helenística, primero bajo la dirección de la Prof. Delia Deli y posteriormente con la Prof. Elena Huber. Durante ese período, gracias a una pasantía de perfeccionamiento, pasó una temporada en el "Dipartimento de Scienze 
de l'Antichità" de la Università Degli Studi di Bari bajo la dirección del Dr. Giuseppe Mastromarco. Integró y dirigió diferentes proyectos de investigación en la Facultad de Humanidades y Artes de la UNR. Fue miembro fundadora del Centro Interdisciplinario de Estudios Europeos en Humanidades y del Centro de Estudios Helénicos de la UNR. Socia de la AADEC, participó como expositora en todos los Simposios Nacionales de Estudios Clásicos en los últimos veinticinco años y de numerosas reuniones académicas en el país y en el extranjero. Publicó varios artículos sobre los avances de su trabajo.

Dos temas la convocaban especialmente: la poesía griega antigua y el sympósion; pero solo uno la obsesionaba: la atractiva figura de Calímaco, a cuya obra dedicó prácticamente toda su vida de investigadora. Lamentablemente, su trabajo en este campo quedó inconcluso y sin darse a conocer por completo.

Quienes tuvimos el placer de compartir con Daniela parte de su intensa vida, sabemos lo imperfectamente humana que era. Alegre, de corazón generoso, afectuosa, solidaria, promovió con modestia el trabajo colectivo sin buscar el lucimiento personal y se opuso férreamente a cualquier tipo de mezquindad individual. De ese humanismo supo hacer una forma de vida. Su inesperada partida, el 1 o de enero de 2016, causó un profundo dolor entre los docentes y alumnos que compartieron con Daniela la actividad académica en el ámbito de los estudios clásicos, y una impotente desesperación en sus amigos, que, también por fuera del aula, disfrutamos de su compañía y cariño desinteresado. Espontáneamente sus alumnos la homenajearon en dos oportunidades, y el Centro de Estudios Helénicos de la UNR, en cuya creación participó con el entusiasmo que solía poner en todo lo que hacía, ha querido también recordarla a través de la I Jornadas de Estudios Clásicos llevadas a cabo durante el mes de octubre de 2016 en la ciudad donde vivió. Desde estas páginas, le dedicamos un recuerdo cariñoso con las palabras de su amado poeta.

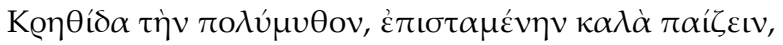

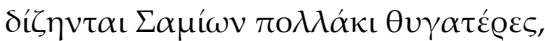

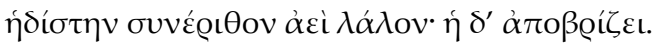

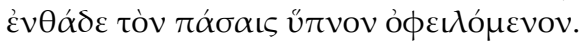

(Calímaco, Epigramas, XVI)

Por Crétide, la de las mil historias, experta en divertidos juegos, preguntan sin cesar las hijas de los Samios;

por la más dulce compañera, la de charla infinita.

Ella duerme aquí el sueño que a todas les está reservado.

Sebastián Carrizo

Universidad Nacional de Rosario 